\title{
TECNOLOGIA DA INFORMAÇÃO, CRIAÇÃO E COMPARTILHAMENTO DO CONHECIMENTO: UM ESTUDO DO SISTEMA INTEGRADO DE SEGURANÇA PÚBLICA NA DIRETORIA DE INVESTIGAÇÕES CRIMINAIS DE SANTA CATARINA
}

\author{
INFORMATION TECHNOLOGY, KNOWLEDGE \\ CREATION AND SHARING: A STUDY OF THE \\ INTEGRATED PUBLIC SAFETY SYSTEM \\ IN THE BOARD OF CRIMINAL \\ INVESTIGATIONS IN SANTA CATARINA
}

Recebido 19/04/2013 Aceito 18/08/2013

Indianara Tavares Pinto da Silva ${ }^{1}$ Clarissa Carneiro Mussi

\section{RESUMO}

Esta pesquisa buscou analisar o papel da tecnologia da informação no campo operacional da Segurança Pública do Estado de Santa Catarina. Mais especificamente, foi orientada pela seguinte questão: como o uso da tecnologia da informação na área da segurança pública influencia a criação e o compartilhamento do conhecimento na investigação criminal da polícia civil formalizada por meio do inquérito policial? Metodologicamente, o estudo foi conduzido a partir da abordagem qualitativa, caracterizando-se como estudo de caso. As técnicas de coleta de dados consistiram de questionários, entrevistas semiestruturadas, análise documental e análise de artefato físico. Para tratamento e interpretação dos dados, utilizaram-se de técnicas da análise de conteúdo. O estudo apontou que a utilização da tecnologia da informação propicia ações que facilitam o compartilhamento, principalmente do conhecimento explícito, e, consequentemente, qualificam as atividades relacionadas à investigação criminal e à formação do inquérito policial. Estas atividades carecem de estratégias que estimulem o compartilhamento do conhecimento tácito e, por conseguinte, a criação do conhecimento. Identificou-se, ainda, que a contribuição da tecnologia à criação e ao compartilhamento do conhecimento depende também de outras variáveis de ordem contextual (como políticas institucionais, por exemplo) e individual (tal como resistência).

Palavras-chave: segurança pública, sistema de informação, tecnologia da informação, gestão do conhecimento

\footnotetext{
${ }^{1}$ Possui graduação em Administração pela Faculdades Integradas Associação de Ensino de Santa Catarina - FASSE/SC. Atualmente é mestranda em Administração pela Universidade do Sul de Santa Catarina - UNISUL. Florianópolis, Santa Catarina, Brasil. E-mail: indianara@sjc.sc.gov.br.

2 Possui graduação em Ciência da Computação pela Universidade Federal de Santa Catarina - UFSC, mestrado em Administração pela Universidade Federal de Santa Catarina - UFSC e doutorado em Administração pela Universidade de São Paulo - USP. Atualmente é professora da Universidade do Sul de Santa Catarina - UNISUL. Florianópolis, Santa Catarina, Brasil. E-mail: mussi.clarissa@ gmail.com.
} 


\section{ABSTRACT}

The aim of this study is to analyze the role of information technology in the field of operation of public safety in the Brazilian state of Santa Catarina. More specifically, it was based on the following research problem: how does the use of information technology in the area of public safety influence the creation and sharing of knowledge in criminal investigations in the civilian police force, by means of police inquiry? From a methodological point of view, the study was conducted using a qualitative approach, having the character of a case study. The data collection techniques included the use of questionnaires, semi-structured interviews and the analysis of documentation and physical artifacts. As far as the treatment and interpretation of the data is concerned, content analysis techniques were employed. The study showed that the use of information technology can provide actions which facilitate sharing, mainly of explicit knowledge, and which, as a result, characterize activities related to criminal investigation and the launching of police inquiries. These activities are lacking in strategies that provide the sharing of tacit knowledge and consequently the creation of knowledge. Moreover, it was found that the contribution of technology to knowledge creation and sharing in the criminal investigation process also depends on other variables of a contextual (e.g. institutional policies) and individual nature (e.g. resistance).

Keywords: public safety, information system, information technology, knowledge management

\section{INTRODUÇÃO}

A sociedade está em contínua transformação, e a história da humanidade comprova esse fato (TOFLER, 1980). As mudanças nos panoramas político, econômico, social e tecnológico exigem mudanças nas estratégias das organizações e constante busca da inovação por meio do conhecimento. Nesse contexto, a Gestão do Conhecimento (GC) vem ganhando espaço tanto na academia quanto na prática organizacional. A GC está intrinsecamente relacionada à capacidade das organizações para criar conhecimento organizacional, disseminá-lo por toda a organização e incorporá-lo aos produtos, serviços e sistemas (NONAKA; TAKEUCHI, 1997). Criação e compartiIhamento do conhecimento constituem-se em processos relacionados à gestão do conhecimento (DAVENPORT; PRUSAK, 1998; VON KROGH, 2012). A criação do conhecimento advém da interação e do compartilhamento de conhecimentos entre os indivíduos, os grupos e a organização (NONAKA; VON KROGH, 2009).

O uso da tecnologia da informação (TI) como suporte aos processos da GC vem sendo defendido por diversos autores (ex.: VON KROGH, 2012). Para Teixeira (2000), o bom emprego da TI na gestão do conhecimento contribui para o desenvolvimento do conhecimento coletivo e do aprendizado contínuo e favorece a integração, tornando mais fácil o compartilhamento de conhecimentos, problemas e perspectivas entre as pessoas de uma organização. Entretanto, a integração entre a GC e as tecnologias é extremamente complexa, pois envolve tanto o gerenciamento de ativos intangíveis de diferentes naturezas (pessoas e conhecimentos tácitos e explícitos) quanto os conhecimentos estruturais que servem de base tecnológica em diversos segmentos (ROSSETTI; MORALES, 2007).

No setor público, considerando que o foco de atuação reside na efetividade dos serviços prestados à sociedade em detrimento de questões relacionadas à concorrência e à vantagem competitiva (SILVA; GONÇALVES, 2011), a GC contribui para um melhor desempenho no fornecimento dos serviços públicos e para o aprimoramento dos relacionamentos interno e externo (WIGG, 2002). A segurança pública, por exemplo, um dos problemas sociais que mais afligem o cidadão, exige a prática de ações diversificadas, particularmente no que se refere à melhoria da qualidade de vida da população. Não obstante, os órgãos de segurança pública são elementos fundamentais nesse processo de melhoria. A instituição estatal legalmente constituída (nas cons- 
tituições federal e estadual) para atuar na apuração dos crimes é a polícia civil, tendo a missão de praticar a investigação criminal, procedendo a um inquérito policial (THOMÉ, 1997).

O inquérito policial reúne informações e conhecimentos que os policiais civis trazem para esclarecer um crime ocorrido, isto é, reúne em um processo tudo o que foi efetivamente investigado e apurado. Contribuem para a formação do inquérito policial: (1) o delegado de polícia, que é a autoridade máxima para tomar decisões; (2) o agente de polícia, que faz a essência da investigação policial pesquisando provas e trazendo-as ao conhecimento do delegado; (3) e o escrivão de polícia, que tem a função de reduzir a termo, isto é, "colocar no papel" todas as diligências realizadas pelo agente e aprovadas pelo delegado.

Ao lado do vasto número de diligências que um policial civil, seja ele delegado, agente ou escrivão, pode fazer para descobrir o autor de um crime, existe uma ferramenta chamada Sistema Integrado de Segurança Pública (SISP) que pode ser usada, a qual possui milhares de informações reunidas a partir de bancos de dados alimentados pela própria polícia. O policial civil tem, assim, a possibilidade de utilizar as informações do SISP aplicando-as diretamente em sua investigação policial em busca de um resultado predeterminado: provar uma circunstância, formalizar uma verdade ou gerar conhecimento. Como ressalta Crawford (1994, p. 22), "conhecimento é entendimento e 'expertise', a capacidade de aplicar a informação a um trabalho ou a um resultado específico". O conhecimento emerge a partir de um engajamento profundo em uma atividade e de práticas sociais (VON KROGH, 2012).

Considerando o exposto, a pesquisa apresentada neste artigo foi orientada pelo seguinte problema: como o uso da tecnologia da informação na área da segurança pública influencia a criação e o compartilhamento do conhecimento na investigação criminal da polícia civil formalizada por meio do inquérito policial? Visando compreender a problemática apresentada, buscouse, mais especificamente: (1) descrever o processo de formação do inquérito policial, as pessoas envolvidas e as suas atribuições neste processo; (2) identificar as funcionalidades e os usuários do SISP, bem como o seu papel na investigação criminal; (3) e identificar fatores facilitadores e/ ou dificultadores do uso da tecnologia como apoio à criação e ao compartilhamento do conhecimento para a investigação criminal.

As seções subsequentes apresentam, respectivamente, alguns fundamentos teóricos sobre a temática abordada, os procedimentos metodológicos utilizados para a realização desta pesquisa, os principais resultados obtidos e as conclusões do estudo.

\section{SISTEMAS DE INFORMAÇÃO, TECNOLOGIA DA INFOR- MAÇÃO E GESTÃO DO CÓNHECIMENTO NA ADMINIS- TRAÇÃO PÚBLICA}

Informação e conhecimento aliados à tecnologia da informação (TI) tornaram-se recursos estratégicos para qualquer tipo de organização (DAVENPORT; PRUSAK, 1998). Neste estudo, entende-se um sistema de informação como um sistema sociotécnico, envolvendo o conjunto de tecnologia da informação (hardware, bancos de dados, software, redes e outros dispositivos), pessoas e processos organizacionais, bem como a integração que estabelecem entre si (DAVIS et al., 1992; AVGEROU, 2002).

Em sentido geral, o termo Gestão do Conhecimento (GC) pode ser entendido como um conjunto de processos sistemáticos que envolvem a criação, a codificação, o compartilhamento e o uso do conhecimento para atingir os objetivos da organização (DAVENPORT; PRUSAK, 1998). A importância das políticas de GC para o setor público brasileiro foi indicada por um estudo efe- 
tuado pelo Instituto de Pesquisa Econômica Aplicada (IPEA, 2005), fundação pública vinculada ao Ministério do Planejamento, Orçamento e Gestão. De acordo com o referido instituto, a GC para as organizações públicas engloba compromisso com a transparência; foco nos processos e não na hierarquia; reutilização de informações e conhecimentos; visão integradora; utilização de novas tecnologias da informação; e foco nas necessidades dos cidadãos.

A criação do conhecimento organizacional, um dos processos da GC, tornou-se um fator estratégico para as organizações, sendo fonte de inovação (NONAKA; TAKEUCHI, 1997; CHEN; TSENG, 2011). De acordo com Choo (2003, p. 403), a "organização cria, organiza e processa a informação de modo a criar novos conhecimentos", combinando a experiência de seus colaboradores a fim de aprender e inovar.

Nonaka e Takeuchi (1997) consideram o conhecimento tácito (pessoal, difícil de ser formulado e comunicado) e o explícito (codificado, transmissível formalmente e sistematicamente) como complementares no processo de criação do conhecimento. O conhecimento tácito e explícito podem ser conceitualmente distinguidos ao longo de um continuum, em que, de um lado, o conhecimento é quase predominantemente tácito e, do outro, quase predominantemente explícito. Grande parte do conhecimento humano encontra-se entre esses dois extremos (NONAKA; VON KROGH, 2009). O "conhecimento humano é criado e expandido através da interação social entre o conhecimento tácito e o conhecimento explícito" (NONAKA; TAKEUCHI, 1997, p. 68).

Essa interação promove o processo denominado conversão do conhecimento, a partir de quatro modos: socialização (de tácito para tácito), externalização (de tácito para explícito), internalização (de explícito para tácito) e combinação (de explícito para explícito). Segundo os referidos autores, esses modos de conversão de conhecimento são um processo cíclico e dinâmico e são imperativos para a criação do conhecimento organizacional. A abordagem dos modos de conversão do conhecimento relaciona a inovação aos conhecimentos tácitos e explícitos da organização, sendo considerada uma das abordagens que "melhor conseguiu trazer o processo social e epistêmico em um modelo coerente" (BINOTTO; SIQUEIRA; NAKAIAMA, 2009, p. 371).

O compartilhamento do conhecimento corresponde à troca de informações, ideias, sugestões e experiências organizacionais relevantes de um indivíduo com outros da organização, constituindo-se em outro processo da GC relacionado à criação do conhecimento (DAVENPORT; PRUSAK, 1998; NONAKA; TAKEUCHI, 1997). Diversas variáveis influenciam o compartilhamento do conhecimento no contexto das organizações, como as relacionadas às características do próprio conhecimento transferido (ex.: a dificuldade de compartilhar o conhecimento está diretamente ligada ao tipo de conhecimento envolvido), às características do transmissor e receptor do conhecimento (ex.: vocabulário/linguagem, insegurança, motivação e confiança) ou, ainda, ao contexto em que o compartilhamento ocorre (ex.: estrutura, cultura e clima organizacional, estilo gerencial e processos) (MATIN et al., 2010; TONET; PAZ, 2006; DAVENPORT; PRUSAK, 1998; SZULANSKI, 2000).

O compartilhamento e a criação o conhecimento podem beneficiar-se do apoio da TI. Como afirmam Davenport e Prusak (1998, p. 149), "a gestão do conhecimento é muito mais que tecnologia, mas a tecnologia certamente faz parte da gestão do conhecimento". A utilização dos recursos de tecnologia da informação, segundo Silva (2004, p. 55), "pode otimizar ainda mais a externalização, internalização, socialização e a combinação do conhecimento nas organizações", modos de conversão do conhecimento apresentados por Nonaka e Takeuchi (1997).

Nesse contexto, os fundamentos teóricos das temáticas estudadas forneceram subsídios para a elaboração de uma ilustração, figura 1, envolvendo, no âmbito da investigação criminal, os temas e conceitos que esta pesquisa aborda. 


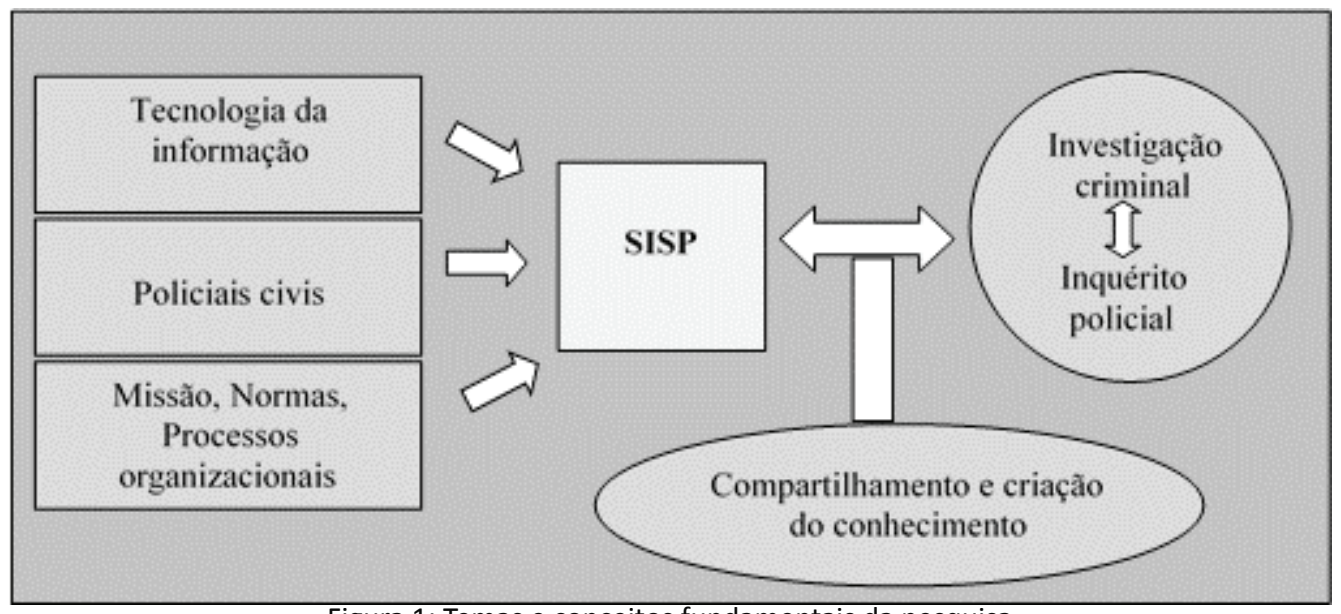

Figura 1: Temas e conceitos fundamentais da pesquisa

Como ilustra a figura 1, o quadrado central representa o Sistema de Informações de Segurança Pública. Sendo um sistema de informação inserido em um contexto organizacional (no caso deste estudo, o contexto da Secretaria de Segurança Pública), é composto por três componentes principais (representados na figura pelos retângulos à esquerda): a tecnologia da informação, que compreende os aparatos tecnológicos do sistema (software, hardware, telecomunicações etc.), os usuários do sistema, ou seja, os policiais civis (delegados, agentes e escrivães de polícia) e a missão, as normas e os procedimentos organizacionais da instituição (polícia civil).

O SISP fornece suporte ao processo de investigação criminal, que, por sua vez, é formalizado por meio do inquérito policial (representados pelo círculo no canto direito da figura). Ao mesmo tempo, a investigação criminal e o inquérito policial fornecem informações ao SISP. Intermediando o uso do SISP pelos policiais civis e a investigação criminal/inquérito policial está a criação e o compartilhamento de informações e conhecimentos (representados pelo oval no canto inferior direito da figura). Isso significa que a investigação criminal é um processo caracterizado por diferentes sujeitos que interagem entre si com o intuito de atingir um objetivo em comum.

Pressupõe-se que, por meio do uso do SISP, informações e conhecimentos podem ser compartilhados por estes sujeitos, assim como novos conhecimentos, ideias e projetos podem ser gerados, qualificando o processo de investigação criminal e a formação do inquérito policial. A figura 1 em conjunto com este pressuposto orientaram a coleta de evidências em campo e a análise dos dados, delineadas segundo os procedimentos metodológicos descritos a seguir.

\section{PROCEDIMENTOS METODOLÓGICOS}

Metodologicamente, a pesquisa foi guiada pela abordagem qualitativa (STRAUSS; CORBIN, 2008) e caracterizou-se como sendo do tipo estudo de caso (YIN, 2005). O caso estudado foi a Secretaria de Segurança Pública de Santa Catarina, mais especificamente a Diretoria Estadual de Investigações Criminais (DEIC), principal órgão investigador da polícia civil, em que se concentram delegados, agentes e escrivães policiais dedicados exclusivamente ao trabalho investigativo em áreas especializadas. A escolha do caso para estudo justifica-se pelo fato de a DEIC ser considerada órgão de excelência na investigação criminal, de forma que os padrões lá estabelecidos na formação do inquérito policial são referência para a prática policial nos demais órgãos do Estado (THOMÉ, 1997).

A DEIC está localizada na cidade de Florianópolis e concentra todas as delegacias espe- 
cializadas, segundo as divisões que compõem a diretoria. O quadro lotacional da DEIC é composto por um total de 81 policiais civis, dos quais 10 são delegados de polícia, 17 são escrivães de polícia e 54 são agentes de polícia.

\subsection{Técnicas de coleta de dados}

A pesquisa qualitativa caracteriza-se pelo uso de um conjunto variado de técnicas de coleta de dados (VERGARA, 2011). As técnicas utilizadas nesta pesquisa foram: questionário, entrevista, análise documental e análise de artefato físico.

Os participantes desta pesquisa foram alocados em dois grupos, aos quais foram aplicadas técnicas de coleta de dados diferenciadas. O primeiro grupo (Grupo 1) foi constituído de todos os policiais civis lotados na DEIC. A este grupo, a técnica de coleta de dados empregada foi o questionário, com o objetivo de ter uma visão geral da utilização do SISP pelos policiais civis da DEIC, abrangendo um número maior de profissionais, e também de complementar as informações das demais técnicas. O questionário foi estruturado com onze questões fechadas de múltipla escolha e cinco questões abertas. Antes do encaminhamento do questionário aos 81 policiais lotados na DEIC, foi realizado um estudo piloto a fim de identificar inconsistências e complexidade das questões. O questionário piloto foi aplicado pessoalmente por um dos pesquisadores a uma turma de pós-graduação constituída por policiais civis. A partir dos comentários e das sugestões, foram realizadas algumas adaptações na versão inicial. Após, o questionário foi enviado via correio eletrônico por meio de um grupo de discussão composto por todos os policiais da DEIC. Dos 81 integrantes do primeiro grupo, apesar do intensivo trabalho de sensibilização para que os policiais participassem da pesquisa, apenas 24 devolveram os questionários devidamente respondidos. Dessa forma, considerou-se como uma limitação do estudo o baixo retorno de respostas dos integrantes do Grupo 1.

Ao segundo grupo (Grupo 2) de participantes da pesquisa, entrevistas foram aplicadas como técnica de coleta de dados. A definição dos participantes da pesquisa do Grupo 2 foi realizada com base em critérios de representatividade, disponibilidade e acessibilidade, obtendo-se um total de nove participantes. Quanto à representatividade, entrevistaram-se policiais dos três diferentes grupos: delegados, escrivães e agentes. Foi selecionado pelo menos um policial de cada uma das seis divisões da DEIC, responsáveis diretamente pelo Inquérito Policial: Divisão de Repressão a Narcóticos, Divisão de Roubos, Divisão de Furtos e Roubos de Veículos, Divisão de Crimes contra o Patrimônio Público, Divisão Anti-Sequestro e Divisão de Escuta Telefônica. Vale salientar que o conjunto dos respondentes, quanto à sua função na $\mathrm{DEIC}$, contemplou desde investigadores até diretores das divisões criminais da DEIC. O critério de disponibilidade implicou entrevistar pessoas que estavam presentes na instituição com tempo disponível para a entrevista durante a etapa de coleta de dados. O critério de acessibilidade implicou entrevistar pessoas residentes no estado de Santa Catarina.

As entrevistas realizadas caracterizaram-se como semiestruturadas (MINAYO, 2004). Buscou-se propiciar um contexto em que os entrevistados expressassem livremente suas respostas e explicitassem experiências por eles vividas. As entrevistas foram realizadas individualmente no local de trabalho dos entrevistados. Antes do início de cada entrevista, o entrevistado recebeu uma carta de apresentação dos pesquisadores e explicação sobre a pesquisa e seus princípios éticos, assinando, então, o termo de consentimento para sua realização. Com o consentimento e a autorização dos entrevistados, as entrevistas foram gravadas por meio de um aparelho gravador e, posteriormente, transcritas de forma literal para a análise dos resultados. Cada entrevista teve em média cinquenta minutos de duração. 
$O$ roteiro de entrevista foi estruturado em seis partes com base nos objetivos e fundamentos teóricos da pesquisa. A parte I - Identificação do entrevistado - visou à caracterização dos participantes da pesquisa. A parte II - Participação na investigação criminal e formação do inquérito - buscou identificar os participantes da investigação criminal e da constituição do inquérito policial, bem como suas atribuições nestes processos. A parte III - Utilização da tecnologia da informação - Sistema Integrado de Segurança Pública (SISP) - objetivou investigar questões relacionadas ao SISP, tais como percepção dos entrevistados sobre o SISP e sua utilização, facilidades e dificuldades no uso do sistema, contribuições do sistema para a investigação criminal, entre outras. A parte IV - Compartilhamento e criação do conhecimento - abarcou questões relacionadas à percepção dos entrevistados quanto à troca e criação de conhecimentos no contexto de trabalho. A parte $\mathrm{V}$ - Tecnologia da informação, compartilhamento e criação do conhecimento - contemplou questões relacionadas à percepção dos participantes da pesquisa quanto à contribuição do SISP para o compartilhamento e a criação do conhecimento com vistas à formação do inquérito policial. Por fim, a parte VI - Sugestões, informações complementares e parecer - buscou obter do entrevistado sugestões para a instituição que atua em relação ao tema da pesquisa, além de seu parecer sobre a pesquisa efetuada. O roteiro de entrevista foi aprimorado a partir da realização de uma entrevista piloto com um delegado de polícia. Vale salientar que os entrevistados não foram identificados no decorrer do trabalho, preservando-se, desse modo, suas identidades em consideração às suas funções exercidas na investigação criminal. A fim de resguardar a privacidade dos entrevistados, os mesmos foram identificados por números, sequencialmente, de " 1 " a " 9 ".

Outra técnica de coleta de dados utilizada foi a análise documental (YIN, 2005). Primeiramente, foram coletadas informações sobre o processo de formação do inquérito policial e analisados documentos que são juntados aos inquéritos policiais e oriundos do SISP. Na sequência, foram coletadas informações que possibilitaram a descrição da estrutura da polícia civil e das atribuições dos participantes da pesquisa. Neste caso, foram resgatados documentos como Estatuto da Polícia Civil, Código do Processo Penal Brasileiro, Lei Complementar n. 453, de 05 de agosto de 2009, Lei n. 7.960, de 21 de dezembro de 1989, entre outros.

Complementando as demais técnicas de coleta de dados, utilizou-se a análise de artefato físico. Os artefatos físicos completam as fontes de evidências, podendo ser "uma tecnologia, uma ferramenta, instrumento, obra de arte ou alguma forma física" (YIN, 2005, p.124). O artefato físico utilizado como fonte de dados desta pesquisa foi a tecnologia da informação integrante do Sistema Integrado de Segurança Pública. Um dos pesquisadores obteve contato direto com a tecnologia em uso na Segurança Pública, o que permitiu uma análise de suas funcionalidades e características, como também uma melhor compreensão da percepção dos entrevistados quando discorreram sobre o SISP.

A partir das diferentes fontes de evidências coletadas pelas técnicas descritas, elaborou-se a sistematização e análise dos resultados, bem como as conclusões da presente pesquisa.

\subsection{Método de análise e interpretação de dados}

Para a análise dos dados e das informações coletados, foram utilizadas técnicas da análise de conteúdo, que consiste em um método de tratamento de dados cujo objetivo é analisar um discurso a fim de identificar o que está sendo dito a respeito de determinado(s) tema(s) (VERGARA, 2011). Nesta pesquisa, fez-se uso da técnica de categorização e da definição de categorias de análise. A categorização consiste na classificação de conteúdos em categorias que reúnem, 
sob um título genérico, um grupo de conteúdos com características comuns (BARDIN, 2004). A forma de categorização utilizada foi baseada no que Laville e Dionne (1999) chamam de grade de análise mista. Tal forma consiste na definição de categorias preliminares (grade fechada) e na consideração de novas categorias (grade aberta) que emergem durante o processo de análise, as quais podem ser acrescidas àquelas anteriormente definidas e indicar a necessidade de subdivisão, inclusão ou exclusão de categorias.

As categorias preliminares foram definidas com base nos objetivos e na estrutura teórica da pesquisa. Assim, estabeleceram-se três categorias de análise com respectivas subcategorias, conforme o quadro 1.

\begin{tabular}{|l|l|}
\hline a) Processo de formação do inquérito policial & $\begin{array}{l}\text { a.1) Etapas } \\
\text { a.2) Pessoas }\end{array}$ \\
\hline & a.3) Atribuições \\
\hline b) Sistema Integrado de Segurança Pública (SISP) & b.1) Módulos e funcionalidades \\
\hline & b.2) Papel na investigação criminal \\
\hline b.3) Facilidades e dificuldades no uso \\
\hline \multirow{2}{*}{ c) Compartilhamento e criação do conhecimento } & c.1) Fatores dificultadores \\
\hline & c.2) Fatores facilitadores \\
\hline & c.3) Papel da tecnologia \\
\hline
\end{tabular}

Quadro 1 - Categorias e subcategorias de análise

Após a transcrição das entrevistas, na íntegra, e a estruturação dos dados coletados a partir das demais técnicas de pesquisa, as informações foram organizadas nas categorias predefinidas. Seguiram-se as diretrizes de Minayo (2004), inicialmente, procedendo-se ao "recorte" de cada entrevista em tópicos de informação, temas ou assuntos relacionados às categorias e subcategorias. Para cada categoria e suas respectivas subcategorias, foi criado um arquivo em que se agruparam os tópicos encontrados e os recortes de cada entrevista a eles correspondentes. Da mesma forma, procedeu-se com os dados coletados a partir das demais técnicas de coleta utilizadas. No caso da análise documental, por exemplo, buscaram-se documentos relacionados às categorias e subcategorias definidas e procedeu-se à leitura dos documentos visando categorizar as informações. No caso da análise de artefato físico, as informações foram categorizadas a partir da interação do pesquisador com o sistema (SISP). A análise e a interpretação dos dados foram, então, realizadas com base nos dados coletados e categorizados, procurando compreender esses dados à luz do referencial teórico utilizado nesta pesquisa.

\section{APRESENTAÇÃO E ANÁLISE DOS DADOS}

Nesta seção, são apresentadas as informações coletadas em campo e as respectivas análises com base nos objetivos propostos para este trabalho. A primeira subseção aborda 0 processo de formação do inquérito policial, as pessoas envolvidas e as suas atribuições. Na segunda subseção, é apresentado o Sistema Integrado de Segurança Pública (SISP), assim como a percepção dos entrevistados sobre o papel deste sistema para a formação do inquérito policial. Por fim, a terceira subseção aborda o compartilhamento e a criação do conhecimento no contexto pesquisado e sua relação com o SISP. 


\subsection{0 inquérito policial, as pessoas envolvidas e suas atribuições}

O inquérito policial é o instrumento pelo qual a investigação criminal é materializada. É por meio dele que se compilam informações a respeito da infração penal, de suas circunstâncias e se resguardam provas futuras, que serão utilizadas em juízo contra o autor do delito. A esse respeito o entrevistado 1 comenta:

[...] normalmente a investigação finaliza com o inquérito policial, concatenando os trâmites desta investigação e também aglutinando nesse inquérito policial todos os elementos colhidos durante a investigação que vão resultar lá na frente em uma denúncia através do Ministério Público.

Participam da formação do inquérito policial delegados, escrivães e agentes de polícia, todos portadores de diploma de nível superior, sendo os delegados portadores de diploma de bacharel em direito. Embora cada um dos três grupos tenha atribuições particulares, todos interagem visando à formação do inquérito.

A função do delegado de polícia frente ao inquérito policial é justamente presidir o processo de formação deste inquérito. $O$ depoimento do delegado explica: "[...] a participação do delegado é fundamental, primeiro porque ele preside o inquérito policial e, segundo, porque dentro dessa presidência há uma responsabilidade sobre exatamente o êxito do processo investigativo" (Entrevistado 3).

O agente de polícia civil tem como principal atribuição investigar, ou seja, levantar provas, trazendo-as para os autos do inquérito policial. O depoimento do agente ilustra isso: "na verdade, a minha participação é praticamente total desde o início, na aquisição de informação, na apuração e notícia do crime, também em colher dados sobre os investigados, sobre o crime, sobre provas e identificação" (Entrevistado 4).

O escrivão de polícia civil é responsável por dar cumprimento às formalidades processuais de polícia judiciária; ele responde por toda a documentação relativa aos inquéritos policiais, tornando-se, nesse ato, o oficial cartorário. 0 depoimento do escrivão entrevistado ilustra o papel dos escrivães durante a investigação criminal e a formação do inquérito policial:

[...] realizandorelatórios, informessobreoandamento dasinvestigações, doslevantamentos fotográficos, filmagens realizadas; buscando dados técnicos complementares, quando disponíveis junto ao Instituto Geral de Perícias, dos depoimentos colhidos junto a testemunhas, vítimas, autores, condutores; auxiliando a autoridade policial nas diligências necessárias para o bom andamento e conclusão do inquérito policial (Entrevistado 9).

Considerando o relato dos policiais civis (delegados, escrivães e agentes), participantes desta pesquisa e a análise documental, foi possível identificar as etapas do processo de formação do inquérito policial. Evidenciou-se que este processo é constituído de informações coletadas durante a investigação criminal, as quais são analisadas e formalizadas por meio do inquérito policial. Um dos entrevistados comenta: "[...] para que o inquérito seja bem formatado evidentemente que se precisa de uma equipe e de uma gama de informações ou de uma fonte de informações em que se possa buscar exatamente a elucidação de participação de autoria dentro desse inquérito policial" (Entrevistado 3).

O processo de formação do inquérito policial inicia a partir da notícia de um crime, um fato específico, que poderá estar incluso ou não no rol dos delitos abrangentes pelo sistema penal vigente. $\mathrm{O}$ setor de plantão da DEIC atende e registra as ditas ocorrências policiais, que po- 
dem ser de várias espécies: ocorrência de um fato (crime ou não), desaparecimento de pessoas, acidente de trânsito, homicídio, tráfico de drogas, entre outras. O policial, após receber a notícia do crime ou do fato propriamente dito, registra o mesmo em um formulário próprio chamado de boletim de ocorrência. A notícia do crime também pode chegar à autoridade policial mediante a requisição do juiz ou do promotor. Quando o delegado recebe a notícia do crime lavrado, investiga a procedência do fato e, em caso afirmativo, baixa portaria para a instauração do inquérito policial.

Instaurado o inquérito policial, devem ser realizadas algumas diligências empreendidas para que a autoridade venha a esclarecer o fato delituoso e suas circunstâncias. A autoridade policial determina o início da investigação policial, que tem como finalidade precípua fazer um levantamento da notícia crime, evidenciando a provável autoria e as demais diligências referentes ao caso.

A investigação policial envolve, dentre outros procedimentos, a pesquisa em diferentes bancos de dados do Sistema Integrado da Segurança Pública. As ferramentas de consulta do sistema policial possibilitam a localização de informações para a investigação, permitindo, ainda, que sejam tomadas medidas preventivas patrimoniais (ex.: bloqueio de contas bancárias ou sequestro de bens móveis ou imóveis dos suspeitos e grampeamento de telefones) e/ou de privação da liberdade (o delegado pode pedir que o juiz decrete a prisão imediata do suspeito). Estas medidas exigem a troca de informações entre o delegado de polícia e o juiz, por meio de procedimento formal e documentado.

O processo de formação do inquérito encerra por meio do relatório elaborado pela autoridade policial e remetido ao juiz competente. Posteriormente, os autos são encaminhados ao órgão do ministério público, para que este adote as medidas pertinentes. Conforme o art. 10 do Código do Processo Penal Brasileiro, o relatório é a última peça do processo de formação do inquérito policial, por meio do qual a autoridade policial dá por concluída sua função de polícia judiciária.

À medida que os procedimentos citados anteriormente vão sendo cumpridos, o inquérito policial vai se formando, principalmente com auxílio do Sistema Integrado de Segurança Pública, conforme é descrito na seção a seguir.

\subsection{O Sistema Integrado de Segurança Pública}

O Sistema Integrado de Segurança Pública (SISP) é um ambiente tecnológico utilizado com o propósito de integrar os bancos de dados e facilitar as ações (prevenção, investigação e inteligência) das unidades que compõem a Secretaria de Segurança Pública do Estado de Santa Catarina. O SISP permite administrar os dados de segurança pública do Estado, sendo reconhecido como uma inovação tecnológica. A esse respeito, o entrevistado 2 relata:

O Sistema Integrado de Segurança Pública, o SISP, é um dos principais sistemas na área da investigação atualmente, em nível de país, porque era um sistema desenvolvido com a polícia no Estado de Santa Catarina e exportado para outros Estados. É o melhor pelo que tenho conhecimento em atividade no País.

O Entrevistado 1 menciona, ainda, que "o efetivo direcionamento às demandas de Segurança Pública foi dado por profissionais especializados nesta área, objetivando tornar o SISP uma ferramenta acessível para todos os policiais".

O SISP dispõe de 11 módulos que integram as principais funções de segurança e investigação, possibilitando a geração de relatórios estatísticos e a investigação de aproximadamente seis milhões de indivíduos cadastrados. Os módulos que compõem o SISP são assim denominados: Investigação Policial, Auto de Apreensão de Adolescente, Auto de Prisão em Flagrante, 
Boletim de Ocorrência, Cartório Policial, Estatística Polícia Civil, Indiciamento, Inquérito Policial, Mandado de Prisão, Penal e Termo Circunstanciado. De acordo com os participantes da pesquisa, os módulos mais utilizados na investigação policial e para a formação do inquérito são: Investigação Policial, Boletim de Ocorrência, Estatística Polícia Civil e Inquérito Policial.

O módulo de Investigação Policial permite ao policial, antes de sair a campo, buscar, junto às bases de dados da Segurança Pública, informações que auxiliem na atividade de investigação e registrar e acompanhar os vários serviços executados nas delegacias de polícia do Estado de Santa Catarina, principalmente na DEIC. Disponibilizando informações para a investigação policial, esse módulo tem o objetivo de manter dados a respeito do indivíduo, possibilitando ao usuário localizar informações distribuídas no universo das bases de dados dos demais módulos do SISP. O módulo de Investigação Policial compreende o Sistema i-SEG (Sistema de Inteligência da Segurança Pública), a rede Infoseg (Informações de Segurança Pública Nacional) e o Sistema i-PEN (Sistema de Informações Prisional), bem como bases de dados que permitem consulta sobre veículos e antecedentes policiais, por exemplo.

O módulo do SISP denominado Boletim de Ocorrência abrange todas as ocorrências registradas nas unidades policiais do Estado de Santa Catarina. O SISP possibilita o cruzamento dos parâmetros indicados com as informações inseridas no registro de ocorrência. Este módulo possui mais de 2.000 retratos falados disponíveis para consulta, que é realizada em tempo real, atingindo o universo de 300.000 prontuários.

O módulo Inquérito Policial permite que o inquérito propriamente dito seja elaborado e registrado no sistema. $O$ entrevistado 1 relata as funcionalidades deste módulo: "o inquérito policial hoje é tocado dentro do SISP, ele já é elaborado dentro do SISP, ali você já tem todas as peças, portaria, relatório [...]". Outra funcionalidade que este módulo oferece é a facilidade na busca por um inquérito policial já instaurado, por meio dos campos referentes aos dados do auto, substituindo a morosa pesquisa em acervos documentais arquivados manualmente.

O módulo Estatística Polícia Civil oferece a possibilidade de geração automática de dados estatísticos e investigativos, como a emissão de relatórios mensais de quantidade de delitos por delegacias e de procedimentos autuados, instaurados e baixados por período. Este módulo permite a busca de um boletim de ocorrência específico cadastrado em qualquer lugar do estado, além de informar a quantidade de boletins de ocorrência registrados, os inquéritos policiais instaurados, as prisões efetuadas e a população carcerária.

De acordo com o Entrevistado 2, o SISP busca gerar, de forma ágil, informações e conhecimentos relevantes para as ações de inteligência, visando aumentar o desempenho destas ações, qualificar as informações, reduzir os índices de criminalidade e aumentar o esclarecimento de delitos. O SISP é visto pelos policiais civis participantes desta pesquisa, de modo geral, como uma ferramenta importante, senão indispensável, à investigação criminal e à formação do inquérito policial. Relatos como os apresentados a seguir ilustram essa questão:

É uma ferramenta, hoje, indispensável (Entrevistado 4).

O SISP é uma ferramenta que dispõe vários dados relevantes para a investigação criminal e para a confecção do inquérito policial (Entrevistado 7).

Não há como imaginar fazer Polícia Judiciária hoje sem um fomento da inteligência policial. Quando se pensa em investigação, em associação disso com meios e métodos modernos de tecnologia, o SISP é ferramental na rotina que não pode ser descartado hoje sob nenhuma circunstância (Entrevistado 5). 
Como enfatizam os entrevistados, a utilidade e a importância do SISP para a rotina de trabalho do policial devem-se à quantidade de informações disponibilizadas, assim como à integração das várias bases de dados que compõem este sistema. É o que demonstram os relatos a seguir:

A plataforma do SISP é um meio importante de investigação porque aglutina dentro dela muita informação sobre uma determinada pessoa. [...] o SISP tem ajudado, sim (Entrevistado 1).

[...] hoje qualquer um que utiliza a ferramenta investigação policial, se ele precisar de um endereço, de um telefone, dos parentes, da filiação, dos pais, dos avós, de veículos que possui, de multas que teve, de boletins de ocorrência que teve, da carteira de habilitação, da foto do cara, está tudo no SISP (Entrevistado 2).

Conforme percepção de alguns delegados entrevistados, o SISP faz parte da rotina de trabalho do policial. Entretanto, fatores concernentes ao perfil do usuário também exercem influência na utilização do sistema. $O$ depoimento que segue ilustra isso.

Faz parte [o SISP] da rotina de trabalho. Existe essa situação do delegado fazer essa determinação, vai de um pouco da característica do profissional, se você tem aquele profissional que eu disse pró-ativo, essa pessoa vai saber o que tem que fazer, vai cumprir a missão dele que é desempenhar a investigação criminal, e trazer esses elementos para o delegado de polícia para que possa instrumentalizar todas essas informações e aglutinar dentro do inquérito policial de maneira concatenada (Entrevistado 1).

Este depoimento, dentre outros obtidos, mostra que a tecnologia por si só não é suficiente para atingir os objetivos da investigação criminal, resgatando a visão de um sistema de informação como o conjunto integrado de tecnologia, pessoas e processos (DAVIS et al., 1992; AVGEROU, 2002).

\subsection{Tecnologia da informação, compartilhamento e criação do conhecimento}

No dia a dia de trabalho na DEIC, a interação entre os profissionais é inerente às atividades realizadas. Por meio dessa interação, informações e conhecimentos são compartilhados nas investigações criminais entre os policiais civis. Os depoimentos transcritos a seguir esclarecem essa situação:

[...] eu sempre procurei trabalhar na medida da parceria, quer dizer, até porque um policial sozinho é um policial sozinho. Você tem que trabalhar em equipe porque do outro lado o meliante tem as informações necessárias para cometer o delito e para fugir da nossa asa, se for o caso, então é preciso que haja a parceria. E busco também, que as pessoas, com quem trabalho, me deixem inteirado daquilo que se está fazendo [...] (Entrevistado 6).

A polícia vive desse tipo de troca de informações. Então o policial que não troca informações, policiais que não buscam noutros setores da própria polícia alguma coisa de conhecimento fica a dever com relação ao próprio inquérito policial, muitas vezes (Entrevistado 3).

Apesar de considerarem importante a troca de informações e conhecimentos para a formação do inquérito policial, nota-se que há fatores que dificultam tanto o compartilhamento quanto a criação de conhecimentos entre os policiais. Na percepção de alguns participantes desta pesquisa, a falta de confiança consiste em um desses fatores, como mostra o seguinte relato: “Primeiramente, vejo que as maiores informações são angariadas antes da instauração do Inqué- 
rito Policial. A grande dificuldade é a falta de confiança no colega, o não saber como ele irá tratar a informação fornecida [...]" (Entrevistado 8). Os depoimentos dos entrevistados corroboram a tese de vários autores no sentido de que a decisão de compartilhar conhecimento depende da relação de confiança entre as pessoas envolvidas.

Alguns entrevistados entendem que as possíveis resistências por parte dos policiais ao compartilhamento do conhecimento podem ocorrer devido ao sigilo que demanda a investigação criminal. Segundo declaração que segue de um dos delegados entrevistados, muitos policiais entendem a questão do sigilo de informações como sonegação de informação:

Devido ao caráter sigiloso que muitos dos Inquéritos Policiais possuem, principalmente com relação à $\mathrm{DEIC}$, há a necessidade da compartimentação de informações, pois caso contrário podem haver prejuízos incalculáveis para as apurações de crimes; além do que, a referida diretoria tem como especialidade a investigação criminal, que por si só requer sigilo, a falta de entendimento legal, leva a muitas pessoas crerem o contrário (Entrevistado 9).

Analisando as respostas dos entrevistados, percebe-se, de fato, a controvérsia no entendimento entre sigilo e sonegação de informações, assunto bastante discutido nas entrevistas. Alguns entendem que o sigilo é necessário para o bom andamento de determinadas investigações, enquanto outros policiais, embora reconheçam o caráter sigiloso da investigação, entendem que sonegar é agir de forma egoísta, no sentido de que as informações são fonte de poder e, como tal, elas têm de ser mantidas em segredo.

Apesar da falta de confiança representar um fator dificultador do compartilhamento e da criação de novos conhecimentos, alguns entrevistados comentam sobre a necessidade e importância da sua existência, bem como sobre sua contribuição à troca de informações entre as equipes que atuam no trabalho investigativo.

[...] quando a chefia imediata compartilha informações, demonstra confiança na equipe e vice-versa, esta é uma forma de se ganhar em equipe (Entrevistado 9).

[...] quando a gente perde a confiança na autoridade que o guia, isso cria um problema seríssimo para a instituição e a recíproca é verdadeira, da mesma forma, a partir do momento que a autoridade policial tem reservas em relação aqueles que trabalham consigo, isso gera mais empedramento de opiniões e menos confiança e menos troca de informações (Entrevistado 5).

Um dos entrevistados acredita que o que chama de "vaidade do policial" e que também tem relação com a ideia de que "conhecimento é fonte de poder, então para que compartilhar?" compromete a troca de informações e conhecimentos entre os colegas no dia a dia de trabalho:

A questão da troca de informações e conhecimento entre policiais civis, eu vejo até com certa preocupação, [...] sempre tem a questão da vaidade do policial, eu sei mais do que o outro, eu não repasso. Essa vaidade prejudica muito. Um cidadão, por exemplo, trabalha numa divisão, sabe que um cara que ele conhece está com um bagulho, mas não fala. Está com droga em casa, mas não fala para o cara: eu vou dar para o pessoal da DEIC. Eu não vou passar para eles. Então a tal dessa vaidade atrapalha muito (Entrevistado 1)

Esse depoimento tem relação com o que dizem Bretas e Poncioni (1999, p. 153) a respeito da falta de compartilhamento de informações entre os policiais: "[...] é a partir de seu conhecimento que o policial se torna poderoso e indispensável, construindo o seu sucesso na carreira. Fazer circular a informação é perder uma parte significativa de seu capital simbólico". 
O entrevistado 4 comenta: "Eu acho que a maior dificuldade que passamos é isso, devido ao medo de perder cargo ou outro tipo de represália, que é normal dentro da Polícia Civil". A dificuldade relatada pelo entrevistado condiz com o ensinamento de alguns autores (como, por exemplo, MATIN et al., 2010 e DAVENPORT; PRUSAK, 1998) que definem como uma barreira individual o medo dos membros da organização de perder a sua estabilidade. As pessoas, às vezes, acreditam que a informação é o que as torna únicas e que, desse modo, compartilhar o conhecimento com os demais significa a perda do seu posto ou cargo no trabalho. $O$ entrevistado 5 também relata o problema de interação em novos locais de trabalho, onde já existem grupos e divisões formadas: "sempre há uma dificuldade natural de engajamento, de fazer parte do grupo", o que, consequentemente, dificulta o compartilhamento do conhecimento.

De forma geral, os participantes desta pesquisa consideram não haver ações da organização/direção que incentivem o compartilhamento e a criação de conhecimento. $O$ entrevistado 4 comenta: "Na verdade as direções são praticamente nulas, quando voltam para o compartilhamento, troca de informações entre os policiais civis [...]". Segundo a fala de outro entrevistado, os novos conhecimentos, ideias e projetos, na grande maioria das vezes, "surgem das necessidades apresentadas, das dificuldades encontradas em cada caso específico, das características e qualidades pessoais ou do grupo" (Entrevistado 9). Além disso, é ressaltada a descontinuidade de projetos específicos na investigação, devido à permanência temporária de um policial em uma determinada área de investigação ou cargo de chefia, conforme explica o entrevistado 6.

[...] não se vê implementações que sejam duradoras e nem que sejam muito transformadoras. Em geral a gente observa projetos que são particulares. São determinados indivíduos que os põem em prática também por um determinado tempo, em geral duram tanto quanto a permanência deles em determinadas áreas ou postos chaves. Então não há uma produção nem um incentivo à produção que seja significativa (Entrevistado 6).

A falta de capacitação e especialização em determinadas áreas específicas da investigação policial é, ainda, um fator considerado limitador do compartilhamento e principalmente da criação de conhecimentos, ideias e projetos. Como diz o entrevistado 5, uma das dificuldades na criação e no compartilhamento do conhecimento "é antes de mais nada a ausência de conhecimentos novos [...], nós não vemos pensadores dentro da Instituição Polícia Civil, com alguma produção literária, com algumas tentativas de inovação". "É preciso investir na formação de pensadores da rotina da atividade policial", afirma o entrevistado 4. De forma similar, o entrevistado 6 comenta: “[...] existe quase que uma estagnação em alguns aspectos. Afora os aprimoramentos que são feitos e transmitidos através da Academia de Polícia, não se vê iniciativa de cursos dentro das delegacias, das regionais [...]". A esse respeito, Giroletti, Lima e Patah (2012, p. 618) defendem que as atitudes inovadoras no âmbito do sistema escolar, das organizações e da sociedade brasileira dependem da implementação de uma educação e de uma cultura voltadas para a inovação, pautadas na valorização do comportamento inovador, de modo que "a inovação deve ser apresentada como desejável, estimulada e recompensada".

Muitas das dificuldades relacionadas à criação e ao compartilhamento do conhecimento apontadas pelos participantes desta pesquisa podem ser identificadas no modelo de compartilhamento do conhecimento de Tonet e Paz (2006). De acordo com os autores, para minimizar essas dificuldades, é necessário principalmente aprimorar os processos de comunicação interpessoal, intergrupal e organizacional; reduzir as inseguranças em relação à organização; criar um clima propício ao voluntarismo, à cooperação e à confiança entre as pessoas; estimular a aquisição de novas competências, a prática da reflexão, a mudança de modelos mentais e a aprendizagem contí- 
nua; buscar a adoção de estilos gerenciais facilitadores do trabalho cooperativo e do comprometimento das pessoas; e adotar políticas que incentivem e valorizem o compartilhamento de conhecimento.

Com relação aos fatores que facilitam o compartilhamento do conhecimento e de informações com vistas à formação do inquérito policial, identificou-se unanimidade nas respostas dos participantes desta pesquisa quanto à tecnologia da informação hoje disponível, mais especificamente ao SISP. Conforme depoimentos obtidos, de forma geral, o SISP contribui para o compartiIhamento do conhecimento por integrar um grande número de dados e informações necessários à investigação criminal, pela rapidez e agilidade com que se pode ter acesso a essas informações e pela capacidade de conectar um grande número de pessoas dispersas geograficamente. Nesse sentido, corrobora o depoimento do entrevistado 5: "[...] com a implementação do SISP houve, no meu entendimento, um enorme avanço, considerável mesmo, na qualidade e na velocidade que temos acesso à informação e também ao maior número de informações disponíveis".

Com a utilização do SISP, observou-se que houve uma padronização de todo o procedimento policial no Estado, principalmente no registro de boletins de ocorrências, que antes era arcaico e não tinha um padrão nos cadastros, pois cada departamento utilizava diversas bases de dados diferenciadas e independentes entre si, não permitindo o compartilhamento e cruzamento de informações constantes na investigação. Uma das formas de compartilhar informações utilizando o SISP é por meio da inserção do inquérito policial dentro do SISP, conforme exposto pelo entrevistado 2:

Bom, agora, recentemente passou-se a fazer o próprio inquérito policial dentro do SISP. Eu acho que é um avanço em nível de País e é um dos primeiros Estados que está tomando essa iniciativa, sem dúvida alguma. E o SISP é o local, a ferramenta adequada exatamente para que no futuro haja um inquérito policial virtual.

Quanto à utilização do SISP contribuir para a criação de novos conhecimentos pertinentes à investigação criminal entre os policiais civis, de forma geral, os participantes desta pesquisa acreditam que o SISP tem potencial para possibilitar a geração do conhecimento. A inserção, o tratamento e a concatenação de informações e dados no sistema pode resultar na geração de um novo conhecimento que venha a contribuir significativamente em uma tarefa específica na investigação.

Embora concordem quanto à contribuição do SISP para a troca e criação de conhecimentos no processo investigativo, os participantes desta pesquisa denotam que isso somente acontece se ocorrerem outras ações no âmbito individual (dos usuários do sistema), institucional e de aprimoramento da própria tecnologia. Nesse sentido, a fala dos participantes corrobora os fundamentos teóricos da pesquisa, confirmando que a tecnologia da informação é uma das variáveis da gestão de conhecimento, em conjunto com outras de caráter contextual e individual.

Além das questões anteriormente abordadas (confiança, estabilidade, vaidade, ações institucionais, descontinuidade de projetos, dificuldades de engajamento em grupos já constituídos), referentes ao contexto organizacional que influenciam o compartilhamento e a criação do conhecimento, independentemente do uso da tecnologia, vários entrevistados trazem outros fatores dificultadores quando questionados sobre o apoio da tecnologia (SISP) aos processos de compartilhamento e criação de conhecimento.

Vários deles referem-se a questões relacionadas ao uso do sistema, mais especificamente à sua alimentação e finalidade de uso. $O$ entrevistado 7, por exemplo, menciona que o SISP pode auxiliar muito o compartilhamento com a seguinte condição: "desde que o SISP seja alimentado de forma correta, com o preenchimento de todos os campos [...]." O entrevistado 8 comenta: "há falta de inserção correta e precisa de dados quando da confecção de um primeiro procedimento ou na alimentação de um já existente". Já a fala do entrevistado 6 remete à finalidade de uso do sistema: 
[...] o acesso deve ficar restrito a um procedimento, a um processo. Se o cidadão faz consultas de quem não tem necessidade nenhuma de ser consultado, ele deveria responder em relatório o porquê daquilo. [...] é preciso que haja uma fundamentação para que essa pesquisa seja feita, efetivamente reiteradas de pessoas que careçam ser investigadas e não de qualquer pessoa com que o agente tenha contato e resolva, no momento de folga, querer pegar dados de qualquer cidadão.

Outros entrevistados abordam questões relacionadas à gestão do sistema (SISP), como a necessidade de treinamento e de um acompanhamento mais efetivo do seu uso. Alguns entrevistados mencionam a necessidade de aprimoramentos do próprio SISP, ação esta que acreditam facilitar e potencializar o compartilhamento de conhecimentos entre os agentes envolvidos na formação do inquérito policial, como, por exemplo: integração com outros órgãos estaduais e federais, disponibilização de outras informações em módulos já existentes e equipamentos (tablets) em viaturas para consulta mais rápida ao SISP.

Os policiais também mencionam necessidades referentes à gestão de TI como um todo que vão além do SISP, tais como problemas relacionados à velocidade da intranet e internet, acesso restrito a redes sociais (onde consideram poder obter informações importantes para a investigação), necessidade de investimentos em hardware para a investigação criminal (ex.: internet móvel, iPads, máquinas digitais, GPS, VPNs, melhoramento do sistema de rádio, filmadoras e sistema de guardião/escuta telefônica mais moderno).

O quadro 2 apresenta, resumidamente, os usuários e as funcionalidades do SISP, bem como os fatores facilitadores e/ou dificultadores do uso da tecnologia como apoio à criação e ao compartilhamento do conhecimento para a investigação criminal.

\begin{tabular}{|c|c|c|c|}
\hline \multirow[t]{2}{*}{$\begin{array}{l}\text { Usuários do } \\
\text { SISP }\end{array}$} & \multirow[t]{2}{*}{$\begin{array}{l}\text { Funcionalidades/ } \\
\text { Módulos do SISP }\end{array}$} & \multicolumn{2}{|c|}{$\begin{array}{c}\text { Uso da TI (SISP) para criação e } \\
\text { compartilhamento do conhecimento }\end{array}$} \\
\hline & & Facilitadores & Dificultadores \\
\hline $\begin{array}{l}\text { Policiais civis } \\
\text { (Delegados, } \\
\text { Escrivães e } \\
\text { Agentes) }\end{array}$ & $\begin{array}{l}\text { Prevenção, Investiga- } \\
\text { ção e Inteligência } \\
\text { - Investigação policial } \\
\text { (i-SEG, Infoseg e i-PEN) } \\
\text { - Boletim de ocorrên- } \\
\text { cia } \\
\text { - Estatística policial ci- } \\
\text { vil } \\
\text { - Inquérito policial } \\
\text { - Auto de apreensão } \\
\text { de adolescente } \\
\text { - Auto de prisão em } \\
\text { flagrante } \\
\text { - Cartório policial } \\
\text { - Indiciamento } \\
\text { - Mandado de prisão } \\
\text { - Penal } \\
\text { - Termo circunstancia- } \\
\text { do }\end{array}$ & $\begin{array}{l}\text { - Agilidade no acesso a infor- } \\
\text { mações e conhecimentos (ex- } \\
\text { plícitos) } \\
\text { - Integração de diferentes } \\
\text { bases de dados necessárias à } \\
\text { investigação criminal } \\
\text { - Conexão de pessoas disper- } \\
\text { sas geograficamente } \\
\text { - Reconhecimento da impor- } \\
\text { tância de um clima de con- } \\
\text { fiança e cooperação } \\
\text { - Padronização do procedi- } \\
\text { mento policial } \\
\text { - Inserção do inquérito policial } \\
\text { no SISP } \\
\text { - Visão sociotécnica do SISP } \\
\text { - Visão do compartilhamento } \\
\text { como fundamental à investi- } \\
\text { gação criminal }\end{array}$ & $\begin{array}{l}\text { - Relação de confiança } \\
\text { - Resistência em compartilhar por } \\
\text { receio de perda de cargo, poder } \\
\text { e status } \\
\text { - Dificuldade de engajamento em } \\
\text { grupos já constituídos } \\
\text { - Falta de ações institucionais de } \\
\text { incentivo à criação e ao comparti- } \\
\text { Ihamento do conhecimento } \\
\text { - Limitações quanto ao compar- } \\
\text { tilhamento do conhecimento tá- } \\
\text { cito } \\
\text { - Descontinuidade de projetos } \\
\text { - Limitações quanto à capacitação } \\
\text { - Problemas na alimentação do } \\
\text { SISP } \\
\text { - Necessidades referentes à ges- } \\
\text { tão da TI }\end{array}$ \\
\hline
\end{tabular}

Quadro 2: Usuários, funcionalidades e fatores facilitadores e dificultadores.

De forma geral, independentemente das dificuldades encontradas, os dados coletados demonstram que o SISP possibilita uma visualização sistêmica de informações de um determinado indivíduo, a partir da identificação e de cruzamentos de um conjunto de informações ali disponíveis, apoiando a troca de conhecimentos, em especial de conhecimentos explícitos, entre os 
policiais civis e, consequentemente, contribuindo para a investigação criminal. Ao mesmo tempo, a investigação criminal e o inquérito policial fornecem informações ao SISP.

A investigação policial inicia-se pela coleta de informações, considerando as circunstâncias do caso. Dependendo da quantidade de informações que o policial obtém e da complexidade das situações possíveis que surgem no caso investigado, ele passa a ter dificuldades de estabelecer as conexões lógicas dos fatos e realizar as associações necessárias entre as pessoas envolvidas, objetos etc. É principalmente nessa situação que a tecnologia se faz necessária, proporcionando ao policial condição de acesso rápido ao conhecimento (explícito) por meio de pesquisas realizadas. A partir do compartilhamento de conhecimentos explícitos por meio do sistema, novos conhecimentos e ideias podem ser gerados, neste caso, a partir dos policiais civis. Como destacam Nonaka e Takeuchi (1997), a criação do conhecimento é uma atividade essencialmente humana e social.

\section{CONCLUSÕES}

Esta pesquisa teve como objetivo geral analisar de que modo o uso da tecnologia da informação influencia a criação e o compartilhamento do conhecimento na investigação criminal da polícia civil formalizada por meio do inquérito policial. Foram abordadas as funções e atribuições dos agentes, escrivães e delegados de polícia em busca do bem maior e da missão da instituição policial, que é realizar a investigação criminal. Para tanto, as etapas do processo de investigação criminal foram descritas. Na sequência, foi apresentado o Sistema Integrado de Segurança Pública (SISP) utilizado na Secretaria de Segurança Pública, seus principais módulos e respectivas funcionalidades. Foi também investigada a percepção dos atores participantes da formação do inquérito quanto ao papel do SISP nesse processo.

Constatou-se que os agentes, escrivães e delegados de polícia, integrantes da Diretoria Estadual de Investigações Criminais (DEIC) - órgão de referência na investigação criminal especializada - veem o SISP como um sistema imprescindível à investigação criminal e formação do inquérito policial, considerando a gama de informações por ele integradas, a velocidade com que se tem acesso a estas informações e a possibilidade de conectar um grande número de atores. Destaca-se a visão dos participantes da pesquisa, que percebem o sistema não apenas como uma tecnologia da informação, ao abordarem em seus depoimentos questões relativas à interação dos usuários policiais civis com a tecnologia e apontarem para a relação da tecnologia com a missão, as normas e os procedimentos institucionais. Isso reflete o fundamento teórico de que um sistema de informação computadorizado não é composto somente pela tecnologia da informação, bem como reforça a necessidade de uma efetiva interação entre seus três componentes: tecnologia, usuários e procedimentos organizacionais.

Quanto à criação e ao compartilhamento do conhecimento, foram identificados fatores favoráveis quando se observa que vários entrevistados relataram que a interação entre os profissionais é inerente às atividades realizadas. Por meio dessa interação, informações e conhecimentos são compartilhados nas investigações criminais entre os policiais civis. Para eles, o crescimento do conhecimento e da informação deve-se ao seu compartilhamento, pois, à medida que se compartiIha uma ideia ou habilidade com outras pessoas, possibilita-se a criação de novos conhecimentos, o que é fundamental para o processo de investigação e formação do inquérito policial.

Contudo, os participantes da pesquisa identificaram algumas dificuldades, que prejudicam e inibem o compartilhamento de informações e conhecimentos no contexto institucional. Em consonância com o referencial teórico, tais dificuldades são de natureza tanto individual quanto organizacional, como, por exemplo: resistência da fonte em repassar o conhecimento 
que detém, por receio de perder status ou poder e de ser substituído; situações desfavoráveis do contexto organizacional para o compartilhamento; capacitação insuficiente dos usuários para a aplicação do conhecimento; falta de confiança entre alguns policiais civis com relação à questão de proteger informações referentes a suas áreas de trabalho.

No entanto, é unânime a percepção dos entrevistados de que a tecnologia da informação (SISP), em consonância com a missão constitucional atribuída à polícia civil no que diz respeito à investigação policial, facilita o apoio à criação e ao compartilhamento de informações e conhecimentos no contexto organizacional da polícia civil, produzindo, portanto, qualidade final no trabalho de investigação criminal. Ao integrar um conjunto de dados, informações e conhecimentos fornecidos por seus usuários, o SISP propicia a interação entre delegados, agentes e escrivães e, consequentemente, o seu compartilhamento.

Fazendo uma analogia com um jogo de "puzzle", à medida que a investigação policial vai sendo conduzida, novas peças (informações) vão sendo integradas ao "puzzle" (sistema), de uma maneira lógica, a partir da intervenção e interpretação do atores policiais. Essa interpretação gera novos conhecimentos. O fato de o próprio inquérito policial estar inserido no sistema e poder ser constituído a partir das contribuições de diferentes atores é evidência do compartilhamento e da possibilidade de criação de conhecimentos. Dessa forma, o SISP aproxima atores policiais entre si e facilita seu acesso a dados, informações e conhecimentos relevantes, contribuindo para o aprimoramento do inquérito policial e da aplicação da pena pela justiça criminal, a partir da utilização da tecnologia da informação de forma efetiva.

A análise dos dados desta pesquisa permitiu, ainda, observar questões relacionadas aos tipos de conhecimento (explícito e tácito) envolvidos no SISP e na investigação criminal. Os conhecimentos compartilhados a partir do uso do sistema constituem-se de conhecimentos explícitos - conhecimentos objetivos que podem ser verbalizados ou escritos, transmitidos facilmente entre os indivíduos. Isso é natural, uma vez que o conhecimento tácito é difícil de ser articulado na linguagem formal, por ser um conhecimento pessoal, subjetivo, incorporado à experiência individual e, consequentemente, difícil de ser transmitido por meio de uma tecnologia.

Percebeu-se, segundo os depoimentos de vários entrevistados, que o processo de investigação criminal e de formação do inquérito policial, constituído de conhecimentos tanto explícitos quanto tácitos, carece do estabelecimento de estratégias que propiciem o compartilhamento do conhecimento tácito. Assim, depreende-se que os processos de conversão do conhecimento (socialização, combinação, internalização e externalização) podem ser apoiados pela tecnologia da informação em parte. No caso deste estudo, a contribuição do SISP para a troca e criação de conhecimentos concentra-se em sua maioria nos processos de combinação e internalização.

Por fim, destaca-se que esta pesquisa permitiu abranger uma gama de assuntos que transcendem a ideia do SISP somente como uma tecnologia da informação, já que abordou as relações interpessoais e a própria estrutura na qual está alicerçada a relação dos policiais com a instituição. Quando solicitado aos policiais para exporem sua percepção sobre a pesquisa realizada, foi possível perceber que a mesma contribuiu para produzir um autoquestionamento daqueles que fazem uso do SISP, fomentando discussões acerca do seu uso, da sua utilidade, da possibilidade do seu crescimento e do seu desenvolvimento para melhor atender a expectativa da formação de inquéritos e realizar a atribuição da Polícia Judiciária.

Como recomendações para estudos futuros, propõe-se a análise da temática apresentada neste artigo em diretorias de investigações criminais de outros estados, bem como o desenvolvimento de pesquisas no âmbito da segurança pública que analisem a influência da tecnologia da informação e de variáveis de ordem contextual e individual às práticas de gestão do conhecimento. 


\section{REFERÊNCIAS}

AVGEROU, C. New socio-technical perspectives of IS innovation in organizations. In: AVGEROU, C.; LAROVERE, R. L. ICT Innovation: economic and Organizational Perspectives. Cheltenham: Edward Elgar, 2002. p. 141-161.

BARDIN, L. Análise de conteúdo. 3. ed. Lisboa: Edições 70, 2004.

BINOTTO, E.; SIQUEIRA, E. S.; NAKAYAMA, M. K. Criação do conhecimento no Agronegócio: estudo de casos. Rev. Adm. UFSM, Santa Maria, v. 2, n. 3, p. 367-384, set./dez., 2009.

BRETAS, M. L.; PONCIONI, P. A cultura policial e o policial civil. In: PANDOLFI, D. C. et al. (Orgs.). Cidadania, justiça e violência. Rio de Janeiro: Fundação Getúlio Vargas, 1999. p. 110-162.

CHEN, C.; TSENG, K. Knowledge transfer and innovation performance of competitive knowledge communities: case of a high-tech firm in Taiwan. African Journal of Business Management, África, v. 5, n. 22, p. 9665-9675, 2011.

CHOO, C. W. A Organização do conhecimento: como as organizações usam a informação para criar significado, construir conhecimento e tomar decisões. São Paulo: SENAC, 2003.

CRAWFORD, R. Na era do capital humano. São Paulo: Atlas, 1994.

DAVENPORT, T. H.; PRUSAK, L. Conhecimento empresarial: como as organizações gerenciam o seu capital intelectual. Rio de Janeiro: Campus, 1998.

DAVIS, G. B.; LEE, A. S.; NICKELS, K. R. et al. Diagnosis of an information system failure. Information \& Management, [S.I.], v. 23, n. 5, p. 293-318, 1992.

GIROLETTI, D. A.; LIMA, R. J. C.; PATAH, L. A. Educação para a inovação. Rev. Adm. UFSM, Santa Maria, v. 5, n. 3, p. 607-624, set./dez., 2012.
INSTITUTO DE PESQUISA ECONÔMICA APLICADA. Gestão do conhecimento na administração pública: texto para discussão n.o 1.095. Brasília: IPEA, 2005.

LAVILLE, C, DIONNE, J. A construção do saber: manual de metodologia da pesquisa em ciências humanas. Porto Alegre: Artes Médicas; 1999.

MATIN, H. Z. et al. Designing and clarifying knowledge sharing model in administrative agencies to improve the performance. European Journal of Economics, Finance and Administrative Sciences, [S.I.], n. 22, maio, 2010.

MINAYO, M. C. S. 0 desafio do conhecimento: pesquisa qualitativa em saúde. 8. ed. São Paulo: Hucitec, 2004.

NONAKA, I.; TAKEUCHI, H. Criação de conhecimento na empresa. Rio de Janeiro: Campus, 1997.

NONAKA, I; VON KROGH, G. Tacit Knowledge and Knowledge Conversion: controversy and advancement in organizational knowledge creation theory. Organization Science, [S.I.], v. 20, n. 3, p. 635-652, 2009.

ROSSETTI, A.; MORALES, A. B. O papel da tecnologia da informação na gestão do conhecimento. Ciência da Informação, Brasília, v. 36, n. 1. p. 124-135, jan./abr. 2007. Disponível em: < http://revista.ibict.br/ciinf/ index.php/ciinf/article/view/795/645 >. Acesso em: 28 jun. 2007.

SILVA, F. A.; GONÇALVEZ, C. A. O processo de formulação e implementação de planejamento estratégico em instituições do setor público. Rev. Adm. UFSM, Santa Maria, v. 4, n. 3, p. 458-476 set./dez., 2011.

SILVA, H. F. N. Criação e compartilhamento de conhecimento em comunidades de prática: uma proposta metodológica. $216 \mathrm{f}$. Tese (Doutorado em Engenharia da Produção) - Universidade Federal de Santa Catarina, 
Florianópolis, 2004.

STRAUSS, A.; CORBIN, J. Basics of qualitative research: techniques and procedures for developing grounded theory. 3. ed. California: Sage Publications, 2008.

SZULANSKI, G. The process of knowledge transfer: a diachronic analysis of Stickness. Organizational Behavior and Human Decision Processes, Philadelphia, v. 82, n. 1, maio, p. 9-27, 2000.

TEIXEIRA FILHO, J. Gerenciando conhecimento. Rio de Janeiro: SENAC, 2000.

THOMÉ, R. L. Contribuição à prática de polícia judiciária. Porto Alegre: Palocci, 1997.

TOFLER, A. A terceira onda. 14. ed. Rio de Janeiro: Record, 1980.

TONET, H.; PAZ, M. G. Um modelo para o compartilhamento do conhecimento no trabalho. Revista de Administração Contemporânea, Curitiba, v. 10, n. 2, p. 75-94, 2006.

VERGARA, S. C. Projetos e relatórios de pesquisa em administração. 13. ed. São Paulo: Atlas, 2011.

VON KROGH, G. How does social software change knowledge management? Toward a strategic research agenda. Journal of Strategic Information Systems, [S.I], v. 21, p. 154-164, 2012.

WIIG, K. M. Knowledge management in public administration. Journal of Knowledge Management, [S.I], v. 6, n. 3, p. 224-239, 2002.

YIN, Robert. Estudo de Caso: planejamento e métodos. 3. ed. Porto Alegre: Bookman, 2005. 